\title{
THE EFFECTS OF SYMMETRICAL AND ASYMMETRICAL SCAFFOLDING ON SPEAKING COMPLEXITY, ACCURACY, AND FLUENCY
}

\author{
Parviz Ghasedi \\ English Department, Faculty of Humanity, University of Zabol, Iran \\ E-mail: ghasedi.p.988@gmail.com \\ Farideh Okati \\ English Department, Faculty of Humanity, University of Zabol, Iran \\ E-mail: farideh.okati@uoz.ac.ir \\ Habibollah Mashhady \\ English Department, Faculty of Humanity, University of Zabol, Iran \\ E-mail: mashhadyh@uoz.ac.ir \\ Nasser Fallah \\ English Department, Faculty of Humanity, University of Zabol, Iran \\ E-mail:nfallah84@yahoo.com
}

APA Citation: Ghasedi, P., Okati, F., Mashhady, H., \& Fallah, N. (2018). The effects of symmetrical and asymmetrical scaffolding on speaking complexity, accuracy, and fluency. Indonesian EFL Journal, 4(1), 1-10. DOI: 10.25134/ieflj.v4i1.793.

Published: 01-01-2018

\begin{abstract}
This experimental study was set ought to explore the efficacy of symmetrical and asymmetrical scaffolding in boosting speaking complexity, accuracy, and fluency among 38 upperintermediate EFL learners. To this end, the participants were assigned into random, homogeneous, and heterogeneous groups. The control group participated in normal speaking classroom, while the experimental groups shared their ideas and collaboratively complete tasks related to 7 lessons of New Interchange 2 during 15 sessions. Two different versions of IELTS speaking test were used as pre/post-test. The data were audio recorded and transcribed for statistical analysis. The results of Multivariate tests revealed that there was a statistically significant difference between the mean scores of control and experimental groups on complexity and fluency. On the other hand, descriptive statistics showed the superiority of heterogeneous groups over homogeneous ones. However, the results of Independent sample t-test indicated that the differences between homogeneous and heterogeneous groups reached the significant level just for complexity not fluency and accuracy. Briefly, the results lead support to the Vegotsky's (1978) socio-cultural theory. The findings and pedagogical implications were discussed in details at the end of the study.
\end{abstract}

Keywords: accuracy, asymmetrical scaffolding, complexity, fluency, symmetrical scaffolding

\section{INTRODUCTION}

From constructivist point of view, learning as a cooperative built in developmental process, must be formed and developed individually or collaboratively (Jenkins, 2000). This school of thought in second language acquisition assumes that learners have to build up their own comprehension through implementing and reflecting on the received feedbacks, rather than memorizing lessons' contents which lead to rote learning (Byerly \& Brodie, 1999).

Generally speaking, the roots of this theory are associated with the works of Piage (1970) and Vegotsky (1978). They claim that, fruitful learning and advancement occur in aimed communication among symmetrical learners with different perspective, point of view, or claim (Piaget, 1977) or through 
affiliation with their proficient partners (Vegotsky, 1978). Considering disclosure as the main tenant of input internalization, Piaget and Inhelder (1969) argue that people generate knowledge and meaning through interfacing with the nature and background knowledge.

Kaufman (2004) cited in (Brown, 2007) asserts that, from this point of view, learning is a formative procedure that includes development and advancement; expanding on prior stored knowledge in the schemata. Cognitive constructivists believe that human beings are inherently roused to progress and improvement, therefore the interaction among learners with equal proficiency levels facilitates learners' progress (Piaget \& Inhelder, 1969). On the other side, the proponents of sociocultural theory note that leaning and progress could not be separated from sociocultural contexts and communications in which the presence of more capable peers seems necessary (Vygotsky, 1978). The supporters of this theory claim that receiving feedbacks from more knowledgeable peers, teachers, or parents give the low capable learners the opportunities to develop their psychological functions to a higher level (Ellis, 2000; Hughes, 2001; Lantolf, 2000).

More recently, the main tenants of cognitive constructivism and sociocultural theory were manifested in symmetrical and asymmetrical scaffolding (Granott, 1993; Izanlu \& Feyli, 2015; Roth \& Radford, 2010). There are substantial evidences that underpin the efficacy of symmetrical and asymmetrical scaffolding in academic contexts (Ableeva, 2010; Cooper \& Robinson, 2014; Gagné \& Parks, 2013; Nguyen, 2013; Roth \& Radford, 2010).

More interestingly, nowadays, developing learners' oral skill and it sub-skills is considered as the chief aim of any language education classroom (Goh \& Burns, 2012). Goh and Burns (2012, p. 165) mention that "not only does the spoken language offer affordances for learning as the main communicative medium of the classroom, but it is also an important component of syllabus content and learning outcomes." On the significant role of speaking in learning the second or foreign language, Celik and Yavuz (2015) numbered four main reasons. These reasons could be summarized as 1) it is the fundamental mean to conduct the communicative role of language, 2) oral ability are particularly relates to brain science and generally relates to human science, 3 ) for most knowing, a language is synonymous with mastering oral skills, and 4) it puts much demands on the target language learners.

Taking this fact into account that, speaking has large proportion in learning the target language (Mackey, 2012; Nation, 2011), we should welcome any attempt to find conscionable ways for improving learner's speaking skills. On the other hand, an inclusive review of the related studies showed that, developing learners' oral skills faced lots of challenges, especially in EFL contexts (Alonso, 2014; Zhang, 2009). Moreover, large portion of studies that were conducted in the domain of scaffolding were focused on the receptive skills. Besides, no study compared the effects of symmetrical and asymmetrical scaffolding on speaking Complexity,

Accuracy, and Fluency (CAF). Therefore, the current study was set out to fill these gaps and shed more light on the efficacy of scaffolding in enhancing speaking CAF.

\section{Symmetrical and asymmetrical scaffolding}

The concept of scaffolding, emerged from cognitive psychology (Donato \& McCormic, 1994), was considered as an effective strategy for human learning and more specifically for teaching and learning basic language skills in EFL or ESL contexts (Ellis, 2008; Wood, Bruner, \& Ross, 1976). Ellis (2008) views scaffolding as a mental process through which less capable learners disguise information dialogically. Research indicates that there are two kinds of scaffolding that seem to have significant place in academic context, namely symmetrical and asymmetrical (Baleghizadeh, Timcheh-Memar, \& Timcheh-Memar, 2010; Roth \& Radford, 2010).

It is assumed that, the main tenants of symmetrical scaffolding go to the heart of cognitive constructivism (Izanlu \& Feyli, 2015). It alludes to the co-constructed advancement of homogeneous learners with 
distinctive ideas, thoughts, and beliefs (Izanlu \& Feyli, 2015). In the Piagetian perspective, the interaction between heterogeneous learners is counter-profitable to reasonable improvement and learning (Granott, 1993). Nguyen (2013) argued that symmetrical group tasks and assignments enhance learners' inspiration, self-confidence, and give them the chance to assemble affinity with each other, which consequently lead to higher achievement. Furthermore, it was found that cooperating in symmetrical groups lead to the development of learners' psychological, affective, and academic skills (Jalilifar, 2010; Law, 2011).

On the other hand, the asymmetrical scaffolding roots in the Vygotsky's (1978) perspective and his notion of Zone of Proximal Development (ZPD). From the Vygotsky's (1978) perspective, the notion of ZPD connote two developmental levels in learners' minds. These levels are called "the actual developmental level" and "the level of potential development" and are defined as "the functions that have already matured; it is the child's ability to solve a problem without any assistance" and "those functions that have not yet matured but are in the process of maturation, functions that will mature tomorrow but are currently in an embryonic state", respectively (Vygotsky, 1978, p. 86). Accordingly, asymmetrical scaffolding could simply be defined as the steady intercession of an expert in the promotion of a learner who tries to solve a problem or carry out a task, but he/she can't do it without others assistance (Mercer, 1995).

Some researchers considered the presence of asymmetrical learners in gathering activities necessary for gaining fruitful results (Guk \& Kellogg, 2007; Lantolf, 2000). Besides, in asymmetrical collaboration providing a setting for co-learning and supporting (emotionally and intellectually) by experts facilitate internalization (Hughes, 2001) and give both novices and experts the opportunities to experience teacher roles (Pishghadam \& Ghadiri, 2011).

A plethora of studies highlighted the vital role of scaffolding in academic context, especially in promoting learners proficiency in basic language skills (Ableeva, 2010; Talley, 2014; Wachyunni, 2015). In a rather different study, Baleghizadeh et al. (2010) investigated the effects of symmetrical versus asymmetrical scaffolding on EFL learners' reading ability. They collected data from 80 elementary EFL learners and came to the conclusion that homogeneous learners' mean score was higher than heterogeneous ones. Such results were not confirmed by Pishghadam and Ghadiri (2011) who collected data from 52 EFL learners through pre-test, post-test, and interview and argued that the presence of more capable learners in groups is a necessity to improve EFL learners' reading skills. Besides, Izanlu and Feyli (2015) claim that heterogeneous group formation results in the effective construction of the basis of cooperation.

\section{Speaking}

Speaking which is viewed as the process of building and sharing meaning (Chaney \& Burk, 1998) to interact directly and immediately with others (Butler, Eignor, Jones, McNama \& Suomi, 2000) is assumed to have three main dimensions; fluency, accuracy, and complexity (Ellis, 2003; Skehan \& Foster, 1999).

Complexity draws attention to the production of continuously more detailed utterances with more noteworthy and complex syntactic structures and put much emphasizes on the association of oral or written outputs (Foster \& Skehan, 1996). Ellis (2005) noted that complexity refers to the learner's capacity to implement complex sentences and structures in their language productions and defined it as the degree to which the produced language is grammatically and lexically varied and complex (Ellis, 2003).

Accuracy manifests the learner's proficiency to avoid errors in language production (Housen \& Kuiken, 2009). Considering accuracy as the language learners' capacity to avoid making error in oral or written outputs, Skehan and Foster (1999, p. 96) state that it reflects "higher levels of control in the language as well as a 
conservative orientation, that is, avoidance of challenging structures that might provoke error".

Fluency relates to "the rapid, smooth, lucid, and efficient translation of thought or communicative intention into language under the temporal constraints of on-line processing" (Lennon, 2000, p. 26). Byrne (1997) regards it as the capacity to convey ones thought precisely, sensibly, and without too much delay. Al-Shareef (2016) defines it as the number of connected lexical morphemes or phrasal expressions that learners can produce in specific time-limit. Generally speaking, the achievement of native like fluency is regarded as the ultimate goal of studding the second or foreign language (Bamanger \& Gashan, 2015).

Research indicates that, there is a competitive relationship among CAF because of the law capability of working memory (Skehan, 2009) or learner's tendency to be more fluent or accurate in the specific situation (Robinson, 2001; Skehan, 2009). More recently, Bei (2013) investigated the impacts of oral narrative task repetition on intermediate and high proficiency adult learners' speaking CAF. The results showed that, the reiteration of narrative tasks improved learners' exactness and their rate of speaking. However, its effects on complexity were not significant. Besides, the findings indicated that the repetition of oral activities promotes speakers' self-perception of meaningfulness and correctness of their outputs.

In a rather different study, Chau (2014) compared the effects of planning with writing, planning without writing and no-planning on L2 learners' speaking CAF. The results of the statistical analysis revealed that, planning oral narratives with and without writing promotes learners' speaking CAF. Likewise, the researcher found no significant differences between the impacts of planning with and without writing on learners' speaking CAF.

As mentioned before, speaking as one of the four major language skills has been reported to play a significant role in learning the target language effectively (Celce-Murcia, 2003). However, teaching oral skills and developing learners' speaking CAF has been one of the main challenges of teachers, scholars, and researchers in teaching and learning field (Alonso, 2014; Ellis, 2000). On the other hand, the efficacy of scaffolding in academic context has been approved by some studies, however their main focuses were on receptive skills (Ableeva, 2010; Wachyunni, 2015) or written outputs (Obeiah \& Bataineh, 2015). Furthermore, no conclusive study compared the effects of symmetrical and asymmetrical scaffolding on learners' speaking CAF. Therefore, this study was set out to fill these gaps and recommends productive propositions for enhancing the CAF of oral outputs. Accordingly, this study was set out to find plausible answers to the following research questions:

1. Is there any significant difference between the effects of placebo, symmetrical, and asymmetrical scaffolding on the speaking fluency, accuracy, and complexity?

2. Is there any significant difference between the effects of symmetrical and asymmetrical scaffolding on the fluency, accuracy, and complexity of EFL learner's oral production?

\section{METHOD}

The participants of the current study were 38 upper-intermediate EFL learners from University of Zabol. Their ages ranged between 19 and 28 years, comprising 22 females and 16 males. All of them were Persian speakers who had no opportunities to communicate with native English speakers during the time of the study. The selection of the participants was done based on the results of Oxford Placement Test (OPT) from a whole population of 85 . Therefore, those who scored between 40-47 were selected as the participants of the study, since based on the OPT manual for interpretation of scores the scores between this range are considered as upper-intermediate level. The selected subjects were specified into three groups, namely Control Group (CG), Symmetrical Scaffolding Group (SSG), and Asymmetrical Scaffolding Group (ASG). Table 1 shows the group specification. 


\begin{tabular}{lccc}
\multicolumn{3}{c}{ Table 1. Groups' specification } \\
\cline { 1 - 3 } & Gender & Total \\
\cline { 1 - 3 } Groups & Male & Female & \\
CG & 7 & 7 & 14 \\
SSG & 5 & 7 & 12 \\
ASG & 4 & 8 & 12 \\
Total & 16 & 22 & 38 \\
\hline
\end{tabular}

The participants of CG were randomly assigned, the learners in SSG were those whose scores on OPT did not differ more than one standard deviation, and the members of ASG were those whose scores differed from others more than one standard deviation.

A public version of IELTS speaking test was used as pre-test. One week after pre-test, the treatments were started. The participants during 15 sessions, twice a week for around 45 minutes each session, covered 7 lessons of Interchange 2. The CG participated in an ordinary speaking class. First, they listened to the audio files from the book and teacher asked them some general questions. Then, they listened carefully and teacher asked them to retell what they heard. Students were supposed to explain their answers and relate their answers to their real life and experiences. Concerning the treatments of experimental groups, at the begging of the first session, the researcher explained the concept and purposes of scaffolding, that by discussing the material with each other and helping each other, they will improve their own comprehension and production abilities.

Two principal tasks that were used in the treatments of SSG and ASG were retelling and decision making. In line with the previous studies (Lee, 2000; Skehan 1996), three main stages of task based instruction, pre-task, main task, and post-task, were implemented in this study. During the pre-task, the samples were scaffolded concerning how to do the tasks and they made aware of the determined outcomes of each task. Likewise, they were inspired during this stage. In decision making task, main task phase, the learners were supposed to discuss their understandings, misunderstanding, ideas, and information to solve a problem or achieve a specific goal in symmetrical and asymmetrical intra-class groups. Concerning retelling task, they were supposed to read the predetermined text of the book, New Interchange 2, then closed their books and retell their comprehension of the read text. In post task stage, the researcher called the name of one member of each intraclass group randomly and gave him/his 5 minutes to retell the outcomes of his/her group cooperation to the class members. On the other hand, for decision making task, they were supposed to give a summary of their group suggestions, results, or relate the proposed problem to the real situation in the university, Zabol University. The sequencing of these tasks in each session was different from the next one. The teacher sequenced them based on the content of each unit. The teacher moved around the class and helps them if necessary. The learners used molding as well as texts and pictures of the book to scaffold each other. Another version of IELTS speaking test was used as post-test to measure learners' speaking CAF at the end of the experimental period. The data were audio recorded and transcribed for statistical analysis.

\section{RESULTS AND DISCUSSION}

This study was set out with the intent of investigating the effects of symmetrical and asymmetrical scaffolding on upperintermediate EFL learner speaking CAF. In the interim, a comparison was made between the impacts of homogeneous and heterogeneous group formation on the quality and quantity of uttered utterances. The collected data after transcribing and coding were interred into SPSS for further analysis. An important issue that seems necessary to be mentioned here is how recorded interviews were scored concerning speaking CAF.

Speech complexity was measured through calculating the number of lexical morphemes per AS-units which was 
considered as a reliable tool to measure learners' speech complexity (Foster, Tonkyn, \& Wigglesworth, 2000; Mehnert, 1998). Accordingly, in the current study of lexical density, dividing the number of uttered open class words by delivered words (Norris \& Ortega, 2009; Rahimpour, 2008) was considered as the indicator of learners' speaking complexity. Furthermore, based on Rahimpour (2008) and Rahimpour and Mehrang (2010) recommendations, the obtained data were multiplied by 100 to made them more tangible

To quantify speech fluency, the researcher divided the quantity of words in learners' outputs by allotted time (Skehan \& Foster, 1999), filers like Um and Unn were considered as pausing (Mehnert, 1998). On the other hand, the author took all of the mispronunciations, grammatical illformedness, and lexical errors into account, following Skehan and Foster (1999), and divided the uttered error-free T-units by all Tunits (Skehan \& Foster, 1997; Mehnert, 1998) to measure speech accuracy.

The first research question investigated the efficiency of symmetrical and asymmetrical scaffolding in boosting learners' speech CAF. To answer the first research question MANOVA was run. The results of descriptive statistics of learners' speech CAF scores during post-test of the study are presented in Table 2.

Table 2. Descriptive statistics for the efficiency of symmetrical and asymmetrical scaffolding

\begin{tabular}{|c|c|c|c|c|c|c|}
\hline & & Groups & $\mathrm{N}$ & Mean & SD & SE \\
\hline \multirow[t]{3}{*}{ Complexity } & Post-test & CG & 14 & 35.366 & 4.097 & 1.095 \\
\hline & & SSG & 12 & 39.150 & 2.140 & .617 \\
\hline & & ASG & 12 & 42.811 & 3.230 & .932 \\
\hline \multirow[t]{3}{*}{ Accuracy } & Post-test & CG & 14 & 64.355 & 3.624 & .968 \\
\hline & & SSG & 12 & 65.458 & 1.970 & .568 \\
\hline & & ASG & 12 & 66.925 & 3.381 & .976 \\
\hline \multirow[t]{3}{*}{ Fluency } & Post-test & CG & 14 & 89.186 & 1.704 & .455 \\
\hline & & SSG & 12 & 90.226 & .615 & .177 \\
\hline & & ASG & 12 & 90.758 & 2.095 & .604 \\
\hline
\end{tabular}

As Table 2 reveals that the $M$ scores of ASG $\left(M_{\text {complexity }}=42.811, M_{\text {accuracy }}=66.925\right.$, $\left.\mathrm{M}_{\text {fluency }}=90.758\right)$ and SSG (M complexity $=39.150$, $\left.\mathrm{M}_{\text {accuracy }}=65.458, \mathrm{M}_{\text {fluency }}=90.226\right)$ are higher than $\mathrm{CG}\left(\mathrm{M}_{\text {complexity }}=35.366, \mathrm{M}_{\text {accuracy }}=64.355\right.$, $\left.\mathrm{M}_{\mathrm{fluency}}=89.186\right)$. For further investigation of the differences among groups MANOVA was run.
Preliminary assumption testing revealed that the assumption of homogeneity of variance-covariance matrices was not violated (Table 3). Besides, a Multivariate test was conducted to investigate the differences between the CG and experimental groups (Table 4).

Table 3. Box's test of equality of covariance matrices

\begin{tabular}{lllll}
\hline Box's M & F & df1 & df2 & Sig. \\
\hline 32.362 & 2.355 & 12 & 5.643 & .005 \\
\hline
\end{tabular}

Table 4. Multivariate tests for the effect of CG, SSG, and ASG on speaking CAF

\begin{tabular}{lllllllc}
\hline Effect & Value & $\mathrm{F}$ & \multicolumn{2}{c}{$\begin{array}{l}\text { Hypothesis } \\
\text { df }\end{array}$} & $\begin{array}{l}\text { Error } \\
\text { df }\end{array}$ & Sig. & $\begin{array}{l}\text { Partial Eta } \\
\text { Squared }\end{array}$ \\
\hline Groups & & & & & & \\
& Pillai's Trace & .518 & 3.960 & 6 & 68 & $.002^{*}$ & .259 \\
& Wilks' Lambda & .486 & 4.781 & 6 & 66 & $.000^{*}$ & .303 \\
\hline
\end{tabular}

*significant at $\mathrm{P}<.05$

As Table 4 reveals, there was a statistically significant difference among the effects of CG, SSG, and ASG, $\mathrm{F}=3.96, \mathrm{P}=$ .002 , Pillai's Trace $=.518$, partial eta squared $=.259$, on the learners' speech CAF. To find out where the differences laid, tests of between-subjects effects were run. 
Table 5. Tests of between-subjects effects for the effect of CG, SSG and ASG on speaking CAF

\begin{tabular}{|c|c|c|c|c|c|c|c|}
\hline Source & Dimensions & $\begin{array}{l}\text { Type III Sum of } \\
\text { Squares }\end{array}$ & $\mathrm{df}$ & $\begin{array}{l}\text { Mean } \\
\text { Square }\end{array}$ & $\mathrm{F}$ & Sig. & $\begin{array}{l}\text { Partial Eta } \\
\text { Squared }\end{array}$ \\
\hline \multirow[t]{3}{*}{ Groups } & Complexity & 359.168 & 2 & 179.584 & 16.391 & $.000^{*}$ & .484 \\
\hline & Accuracy & 42.711 & 2 & 21.355 & 2.203 & .126 & .112 \\
\hline & Fluency & 16.779 & 2 & 8.390 & 3.254 & $.05^{*}$ & .157 \\
\hline
\end{tabular}

significant at $\mathrm{P}<.05$

As shown in Table 5, the differences that reach statistical significance were belonged to complexity, $\mathrm{F}=16.391, \mathrm{p}=.000$, partial eta squared $=.484$, and fluency, $\mathrm{F}=$ $3.254, \mathrm{p}=.05$, partial eta squared $=.157$. Consequently, it could be claimed that symmetrical and asymmetrical scaffolding lead to the production of more fluent and complex speech.

These findings correspond to the general tenants of scaffolding, arguing that aimed negotiations, in which a plethora of opportunities for testing understandings are provided, lead to internalization of available outputs and advancement (Roth \& Radford, 2010). Similarly, Leloup and Ponterio (2005) consider peer interaction as a fundamental element for discourse advancement. Besides, such findings are bolstered by similarly previous research on reading, writing, and listening (Ableeva, 2010; Obeiah \& Bataineh, 2015; Wachyunni, 2015).

The reason for the superior speaking performance of the SSG and ASG may be attributed to the fact that in amid coordinated efforts and transaction exercises the sentiment necessities to give and receive feedbacks, telling and hearing various opinions, and mutual supports to reach a predetermined specific objectives (regarded as the performance of the hole group) inspired the language learners to feel greater obligations to find plausible answers to justify their miss/understandings, consequently lead to speech development. Additionally, the lower impact of SSG and ASG on speech accuracy could be justified through considering the fact that conveying meaning and intention received, not linguistics structures, draw learners' focal attention during interactions.

The second research question compared the efficacy of symmetrical and asymmetrical scaffolding in enhancing speaking CAF. The inspection of the $\mathrm{M}$ scores (Table 2) indicated that the M scores of ASG were higher than SSG which indicates that asymmetrical scaffolding has more fruitful and effective impacts on speaking CAF than symmetrical one. Therefore, a series of Independent sample t-test were conducted to investigate whether the difference between SSG and ASG were statistically significant or not.

Table 6. Independent sample t-test for the efficiency of symmetrical scaffolding

\begin{tabular}{llllccl}
\hline & $\mathrm{F}$ & $\mathrm{t}$ & $\mathrm{df}$ & $\begin{array}{c}\text { Sig. } \\
(2 \text {-tailed })\end{array}$ & M Difference & $\begin{array}{l}\text { Std. Error } \\
\text { Difference }\end{array}$ \\
\hline Complexity & 3.128 & -3.273 & 22 & $003^{*}$ & -3.660 & 1.118 \\
Accuracy & 3.068 & -1.298 & 22 & .208 & -1.466 & 1.129 \\
Fluency & 16.824 & -.843 & 12.882 & .414 & -.531 & .630 \\
\hline
\end{tabular}

*significant at $\mathrm{P}<.05$

Table 3 indicates no significant differences between the effects of SSG and ASG concerning accuracy $(\mathrm{F}=3.068, \mathrm{t}=$ $1.298, \mathrm{df}=22, \mathrm{p}>.05)$ and fluency $(\mathrm{F}=16.824$, $\mathrm{t}=-.843, \mathrm{df}=12.882, \mathrm{p}>.05)$. However, the differences between experimental groups' complexity scores $(\mathrm{F}=3.128, \mathrm{t}=-3.273, \mathrm{df}=$ $22, \mathrm{p}=.000)$ were statistically significant.
The second research question compared the impacts of symmetrical and asymmetrical scaffolding on speaking CAF. The findings showed that the differences between two groups were significant just for speech complexity; however the M scores of ASG $\left(M_{\text {accuracy }}=66.925, M_{\text {fluency }}=90.758\right)$ were higher than SSG $\left(M_{\text {accuracy }}=65.458\right.$, $\left.\mathrm{M}_{\text {fluency }}=90.226\right)$. It means that, asymmetrical 
scaffolding has more fruitful and beneficial effects on speaking CAF than symmetrical scaffolding. In sum, the results lend support to the Vygotsky's (1978) socio-cultural theory. Besides, Izanlu and Feyli (2015) note that asymmetrical group outperformed the symmetrical group on grammatical accuracy. However, the results conflict with those found by Maftoon and Ghafoori (2009), who observed no differences between the effects of homogeneous and heterogeneous group activities on writing skills, and that of Baleghizadeh et.al. (2010), claiming that symmetrical scaffolding had more effective results on reading comprehension.

Such outcomes could be defended through considering the benefits of interaction among participants who were more knowledgeable in different linguistics era such as pronunciation, lexical, grammatical, discourse knowledge, and cultural information. Therefore, when such students gathered together, they can support each other in constructing well-formed structures which are not grammatically or lexically ambiguous.

\section{CONCLUSION}

The major aim of the current study was exploring the efficacy of symmetrical and asymmetrical scaffolding in boosting upperintermediate EFL learners' speech CAF. The results demonstrated that, gathering works or exercises, symmetrically or asymmetrically, significantly affected speaking subcomponents, especially on complexity and fluency. Therefore, it seems that a great part of the EFL learners' deficiency in speaking sub-skills linked to the implementation of traditional teacher-centered methods of teaching like Grammar Translation or Audio Lingual Method (Behroozizad, Nambiar, \& Zaini, 2014). Furthermore, the findings uncovered that the presence of more proficient speakers in groups made the novices aware of the differences that existed between their oral outputs and that of more capable peers concerning $\mathrm{CAF}$, which inspired them to resemble more proficient speakers and produce more accurate lexically rich utterances fluently.
Based on the findings of the current study some pedagogical implications are suggested:

1. Educational policy makers and supervisors are recommended to conduct training programs for pre-service and in-service teachers on the main notions of scaffolding. Furthermore, teachers need training on how to manage student-centered classrooms.

2. Teachers ought to set the grounds and provide learners with abundant co-learning opportunities.

3. Concerning group formation, it is suggested that the educators select group members based on the learners proficiency level, not their gender, friendship, or age.

One of the big limitations of the current study was the limited number of participants (22 female and 16 male), beside the selection of learners were restricted to upper intermediate level. Moreover, a subset of potential measures of complexity (lexical density) was used to measure learners' speaking complexity. Therefore, repeating similar study involving larger participants with various capability levels, elementary, intermediate, and advanced, and implementing various indicators of complexity (AS-units or syntactic variety) may lead to more fruitful outcomes.

\section{REFERENCES}

Ableeva, R. (2010). Dynamic assessment of listening comprehension in second language learning (Unpublished PhD Thesis). Pennsylvania State University, Pennsylvania.

Alonso, A. R. (2014). Teaching speaking: An exploratory study in two academic contexts. Porta Linguarum, 22, 145-160.

Al-Shareef, S. Y. (2016). The impact of task repetition on fluency, accuracy, and complexity. International Journal of English Language Teaching, 4(2), 30-49.

Baleghizadeh, S., Timcheh-Memar, H., \& TimchehMemar, A. (2010). The effect of symmetrical versus asymmetrical scaffolding on English reading comprehension of EFL learners. Studies in Literature and Language Journal, 1(7), 104-111.

Bamanger, E. M., \& Gashan, A. K. (2015). The effect of planning time on the fluency, accuracy, and complexity of EFL learners' oral production. Journal of Educational Sciences, 27(1), 1-15.

Behroozizad, S., Nambiar, R. M. K., \& Zaini, A. (2014). Sociocultural theory as an approach to aid EFL learners. The Reading Matrix, 14(2), 217226. 
Bei, G. X. (2013). Effects of immediate repetition in 12 speaking tasks: A focused study. English language teaching, 6(1), 11-19.

Brown, H. D. (2007). Principles of language learning and teaching $\left(5^{\text {th }}\right.$ Ed.). New York: Pearson Longman.

Butler, F., Eignor, D., Jones, S., McNamara, T. F., \& Suomi. B. (2000). TOEFL 2000 speaking framework: A working paper.

Byerly, G., \& Brodie, C. S. (1999). Information literacy skills models: Defining the choices. In K. Barbara (Ed.), Learning and libraries in an information age (pp. 54-82), Littleton: Libraries Unlimited.

Byrne, D. (1997). Teaching oral English. Malaysia: Longman Group.

Celce-Murcia, M. (2003). Teaching English as a second or foreign language. Boston: Heinle.

Celik, O., \& Yavuz, F. (2015). The relationship between speaking grades and listening grades of university level preparatory students. Elsevier, Procedia-Social and Behavioral Sciences 197, $2137-2140$.

Chaney, A. L., \& Burk, T. L. (1998). Teaching oral communication in grades $K-8$. Boston: Allyn \& Bacon

Chau, H. T. (2014). The effects of planning with writing on the fluency, complexity, and accuracy of L2 oral narratives (Unpublished PhD Thesis). Michigan State University, Michigan.

Cooper, J. L., \& Robinson, P. (2014). Using classroom assessment and cognitive scaffolding to enhance the power of small-group learning. Journal on Excellence in College Teaching, 25(3\&4), 149161.

Donato, R., \& McCormick, D. E. (1994). A sociocultural perspective on language learning strategies: The role of mediation. Modern Language Journal, 78(4), 453-64.

Ellis, R. (2000). Task-based research and language pedagogy. Language Teaching Research 4(3), 193-220.

Ellis, R. (2003). Task-based language learning and teaching. Oxford: Oxford University Press.

Ellis, R. (2005). Principles of instructed language learning. Asian EFL Journal, 7(3), 1-16.

Ellis, R. (2008). The study of second language acquisition. Oxford: Oxford University Press.

Fitzgerald, J., \& Graves, M. F. (2004). Scaffolding reading experiences for English language learners. Norwood, MA: Christopher-Gordon.

Foster, P., \& Skehan, P. (1996). The influence of planning on performance in task-based learning. Studies in Second Language Acquisition, 18(3), 229-324.

Foster, P., Tonkyn, A., \& Wigglesworth, G. (2000). Measuring spoken language: A unit for all reasons. Applied Linguistics, 21, 354-375.

Goh, C. C. M., \& Burns, A. (2012). Teaching speaking: A holistic approach. New York: Cambridge University Press.
Granott, N. (1993). Patterns of interaction in the coconstruction of knowledge: Separate minds, joint effort, and weird creatures. In R. H. Wozniak, \& K. W. Fischer (Eds.), Development in context: Acting and thinking in specific environments (pp. 183-207). Hillsdale, NJ: Erlbaum.

Guk, I., \& Kellogg, D. (2007). The ZPD and whole class teaching: Teacher-led and student-led interactional mediation of tasks. Language Teaching Research, 11(3), 281-299.

Housen, A., \& Kuiken, F. (2009). Complexity, accuracy and fluency in second language acquisition. Applied Linguistics, 30(4), 461-473.

Hughes, A. (2001). The teaching of language to young learners: Linking understanding and principles with practice, In Faber, P., Gewehr, W., Raya, M. J., \& Peck, A. J. (Eds.), Effective foreign language teaching at the primary level: Focus on the teacher (pp.17-24), Peter Lang.

Izanlu, M., \& Feyli, M. (2015). The effects of symmetrical and asymmetrical scaffolding on university students' grammar acquisition. Journal of Advances in English Language Teaching, 3(6), 106-115.

Jalilifar, A. R. (2010). The status of theme in applied linguistics articles. Asian ESP Journal. Autumn Edition, 6(2), 7-39.

Jenkins, E. W. (2000). Constructivism in school science education: Powerful model or the most dangerous intellectual tendency? Science \& Education, 9(6), 599-610.

Kaufman, D. (2004). Constructivist issues in language learning and teaching. Annual Review of Applied Linguistics, 24, 303-319.

Lantolf, J. P. (2000). Sociocultural theory and second language learning: Recent advances. Oxford: Oxford University Press.

Law, Y. K. (2011). The effects of cooperative learning on enhancing Hong Kong fifth graders' achievement goals, autonomous motivation and reading proficiency. Journal of Research in Reading, 34(4), 402-425.

Leloup, J. W., \& Ponterio, R. (2005). Technology and foreign language instruction: Where we have been, where we are now, where we are headed. ACTFL, 9, 153-174.

Lennon, P. (2000). The lexical element in spoken second language fluency. In Perspectives on fluency (pp. 25-42). University of Michigan.

Mackey, A. (2012). Input, interaction and corrective feedback in L2 classrooms. Oxford: Oxford University Press.

Maftoon, P., \& Ghafoori, G. (2009). A comparative study of the effect of homogeneous and heterogeneous collaborative interaction on the development of EFL learners' writing skill. The Journal of Applied Linguistics, 2(1), 128-158.

Mehnert, U. (1998). The effects of different lengths of time for planning on second language performance. Studies in Second Language Acquisition, 20(1), 83108. 


\section{Parviz Ghasedi, Farideh Okati, Habibollah Mashhady, \& Nasser Fallah}

The effects of symmetrical and asymmetrical scaffolding on speaking complexity, accuracy, and fluency

Mercer, N. (1995). The guided construction of knowledge: Talk amongst teachers and learners. Clevedon: Multilingual Matters.

Nation, I. S. P. (2011). Second language speaking. In Hinkel, E. (Ed.), Handbook of research in second language teaching and learning. New York: Routledge.

Nguyen, M. H. (2013). EFL students reflections on peer scaffolding in making a collaborative oral presentation. English Language Teaching, 6(4), 6473.

Norris, J. M., \& Ortega, L. (2009). Towards an organic approach to investigating CAF in instructed SLA: The case of complexity. Applied Linguistics, 30, 555-578.

Obeiah, S. F., \& Bataineh, R. F. (2015). Does scaffolding-based instruction improve writing performance? The case of Jordanian EFL Learners. Lublin Studies in Modern Languages and Literature, 39(2), 106-123.

Piage, J. (1970). The science of education and the psychology of the child. New York: Basic Books.

Piaget, J., \& Inhelder, B. (1969). The psychology of the child. New York: Basic Books.

Pishghadam, R., \& Ghardiri, S. (2011). Symmetrical or asymmetrical scaffolding: Piagetian vs.

Vygotskyan views to reading comprehension.

Journal of Language and Literacy Education, 7(1), 49-64.

Rahimpour, M. (2008). Implementation of task- based approaches to language teaching. Research on Foreign Languages Journal of Faculty of Letters and Humanities, 41, 45- 61.

Rahimpour, M., \& Mehrang, F. (2010). Investigating effects of task structure on EFL learner's oral performance. English Language Teaching, 3(4), $10-17$.
Robinson, P. (2001). Task complexity, task difficulty, and task production: Exploring interactions in a componential framework. Applied Linguistics, 22 (1), 27-57.

Roth, W. M., \& Radford, L. (2010). Re/thinking the zone of proximal development (symmetrically). Mind, Culture, and Activity, 17, 299-307.

Skehan, P. (2009). Modeling second language performance: Integrating complexity, accuracy, fluency and lexis, Applied Linguistics, 30(4), 510532.

Skehan, P., \& Foster, P. (1997). Task type and task processing conditions as influences on foreign language performance. Language Teaching Research, 1(3), 185-211.

Skehan, P., \& Foster, P. (1999). The influence of task structure and processing conditions on narrative retellings. Language Learning, 49, 93-120.

Talley, P. (2014). Students' responses to scaffolded learning in the Asian university ESL classroom. International Journal of Business and Social Science, 5(3), 235- 244.

Vygotsky, L. S. (1978). Mind in society: The development of higher psychological processes. Cambridge, MA: Harvard University Press.

Wachyunni, S. (2015). Scaffolding and cooperative learning effects on reading comprehension and vocabulary knowledge in English as a foreign language (Unpublished $\mathrm{PhD}$ thesis). University of Groningen, Groningen.

Wood, D., Bruner, J. S., \& Ross, G. (1976). The role of tutoring in problem solving. Journal of Child Psychology and Psychiatry, 17(2), 89-100.

Zhang, S. (2009). The role of input, interaction, and output in the development of oral fluency. English Language Teaching, 2(4), 91-100. 